\title{
Literature Review: Herbal Medicine Treatment after Large-Scale Disasters
}

\author{
Shin Takayama, ${ }^{*}$ Soichiro Kaneko, ${ }^{*}$ Takehiro Numata, ${ }^{*}$ Tetsuharu Kamiya,* \\ Ryutaro Arita,* Natsumi Saito,* Akiko Kikuchi,* Minoru Ohsawa,* \\ Yoshitaka Kohayagawa ${ }^{\dagger}$ and Tadashi Ishii* \\ *Department of Education and Support for Regional Medicine \\ Department of Kampo Medicine, Tohoku University Hospital \\ 1-1, Seiryomachi, Aobaku, Sendai City, Miyagi Prefecture 980-8574, Japan \\ †National Disaster Medical Center, 8-15 Oota-machi \\ Fukushima Prefecture 960-8068, Japan
}

Published 27 September 2017

\begin{abstract}
Large-scale natural disasters, such as earthquakes, tsunamis, volcanic eruptions, and typhoons, occur worldwide. After the Great East Japan earthquake and tsunami, our medical support operation's experiences suggested that traditional medicine might be useful for treating the various symptoms of the survivors. However, little information is available regarding herbal medicine treatment in such situations. Considering that further disasters will occur, we performed a literature review and summarized the traditional medicine approaches for treatment after large-scale disasters. We searched PubMed and Cochrane Library for articles written in English, and Ichushi for those written in Japanese. Articles published before 31 March 2016 were included. Keywords "disaster" and "herbal medicine" were used in our search. Among studies involving herbal medicine after a disaster, we found two randomized controlled trials investigating post-traumatic stress disorder (PTSD), three retrospective investigations of trauma or common diseases, and seven case series or case reports of dizziness, pain, and psychosomatic symptoms. In conclusion, herbal medicine has been used to treat trauma, PTSD, and other symptoms after disasters. However, few articles have been published, likely due to the difficulty in designing high quality studies in such situations. Further study will be needed to clarify the usefulness of herbal medicine after disasters.
\end{abstract}

Keywords: Disaster; Herbal Medicine; Kampo Medicine; Traditional Chinese Medicine; Review.

Correspondence to: Dr. Shin Takayama, Department of Education and Support for Regional Medicine, Department of Kampo Medicine, Tohoku University Hospital, 1-1, Seiryomachi, Aobaku, Sendai City, Miyagi Prefecture 980-8574, Japan. Tel: (+81) 22-717-7507, Fax: (+81) 22-717-7508, E-mail: takayama@med.tohoku.ac.jp

This is an Open Access article published by World Scientific Publishing Company. It is distributed under the terms of the Creative Commons Attribution 4.0 (CC-BY) License. Further distribution of this work is permitted, provided the original work is properly cited. 


\section{Introduction}

Large-scale natural disasters, such as earthquakes, tsunamis, volcanic eruptions, or typhoons, occur worldwide. In these emergencies, governments and the international community must respond with relief and support activities. In Japan, the last 25 years have seen the Great Hanshin Awaji earthquake of 1995, the Niigata Chuetsu earthquake of 2004, the Great East Japan earthquake and tsunami of 2011, and the Kumamoto earthquake of 2016. In the early phases of disasters, self-defense forces, police, and fire personnel rescued victims. Disaster medical assistant teams provided medical relief, including hospital support, patient transfer within the area, wide-area medical transport, and evacuation and transfer of hospitalized patients (Ishii, 2011).

In a large-scale disaster, damage may be severe or affect a greater area. These situations take longer to resolve, and survivors are often evacuated to shelters or evacuation centers. In shelters, long-term evacuees complain of numerous health problems, including infectious disease, pain, insomnia, or chronic disease (Inoue et al., 2014; Tokuda et al., 2014). The Japanese Medical Association Team, the Disaster Relief Project Team of the Japanese Primary Care Association, and other multi-disciplinary medical assistance teams provide medical support. Teams consist of doctors, nurses, pharmacists, and sometimes physical therapists or acupuncturists (Liu et al., 2012).

Since ancient times, traditional Chinese and Japanese (Kampo) medicine has been used to treat infection, trauma, and pain. Japanese doctors use Kampo formulae as basic prescriptions. Kampo formulas are covered by the Japanese government health insurance. In addition to quality, Kampo extract preparations have advantages, including ease of preparation and transport, and conservation of the environment. A recent investigation reported that over $80 \%$ of Japanese doctors use Kampo preparations. Based on the experience of our medical support operation after the Great East Japan earthquake and tsunami, Kampo medicine may also be useful in treating the various conditions of disaster survivors (Takayama et al., 2011).

However, little information is available regarding the indications, duration of treatment, effectiveness, and adverse effects of traditional medicine in disaster situations. In this study, we performed a literature review and summarized the use of herbal medicine after disasters.

\section{Methods}

Literature Search

We searched PubMed and Cochrane Library for articles written in English, and Ichushi for those written in Japanese. The articles were published from the inception date of the database to 31 March 2016. We used the following search strategy: (1) Disaster; (2) Earthquake; (3) Tsunami; (4) East Asian Traditional Medicine; (5) Kampo Medicine; (6) Chinese Traditional Medicine; (7) Chinese herbal drugs; (8) Herbal medicine; (9) Medicinal plant; (10) Plant components; (11) Plant extracts; (12) Phytotherapy; (13) Phytomedicine; (14) Kampo; (15) Oriental medicine; (16) Japanese Traditional Medicine; (17) 
\#1-16 in Japanese; (18) \#1 OR \#2 OR \#3; (19) \#4 OR \#5 OR \#6 OR \#7 OR \#8 OR \#9 OR \#10 OR \#11 OR \#12 OR \#13 OR \#14 OR \#15 OR \#16 OR \#17; (20) \#18 AND \#19.

\section{Selection Criteria}

We included articles published in English or Japanese that were related to herbal medicine treatment after a disaster. Physical therapy, massage therapy, acupuncture, and acupuncturerelated techniques were excluded.

\section{Article Selection}

Two reviewers (S.T. and S.K.) independently assessed the relevance of the retrieved articles by title and abstract. Unsuitable studies were excluded and the full texts of all remaining articles were obtained and screened by two independent groups of reviewers (S.T. and S.K., and T.N. and A.K.) for eligibility. When reviewers disagreed, all authors reviewed the full-text. Disagreements were resolved via discussion and consensus.

\section{Data Extraction}

Two independent researchers (S.T. and S.K.) categorized eligible articles. Information from the articles was extracted and tabulated, and eligible studies were classified according to study design, type of disaster, subjects, type of intervention and control, endpoints, results, and adverse effects. Articles with elusive data presentation were rated as unclear.

\section{Results}

\section{General Aspects}

By searching electronic database, 119 potential articles were identified. Sixty-eight articles were excluded, by title or abstract, during the initial screening. The full text of 39 articles was obtained (Fig. 1). One article identified by a manual search was added later. Twelve articles, published between 2008 and 2015, met our inclusion criteria (Table 1). Most were published from Japan (10 of 12; 83.3\%) (Takayama et al., 2011; Kimura and Sato, 2012; Kuwahara, 2012; Mitsufuji et al., 2012; Nakae et al., 2012; Raimura, 2012; Watanabe, 2012; Takayama et al., 2013; Numata et al., 2014a; Akazawa, 2015) and China (2 of 12; 16.6\%) (Meng et al., 2011; Tianhong et al., 2014). Six articles were published in English $(50 \%)$ and six in Japanese (50\%). Two were randomized controlled trials (RCTs) describing the effects of herbal medicine in patients with post-traumatic stress disorder (PTSD) after a disaster (Meng et al., 2011; Numata et al., 2014a). Four retrospectively investigated the treatment of trauma, primary care conditions, and dizziness (Takayama et al., 2011; Kimura and Sato, 2012; Nakae et al., 2012; Tianhong et al., 2014). Six case reports or case series described the treatment of pain (Kuwahara, 2012; Akazawa, 2015), dizziness (Kuwahara, 2012; Mitsufuji et al., 2012), psychosomatic symptoms 


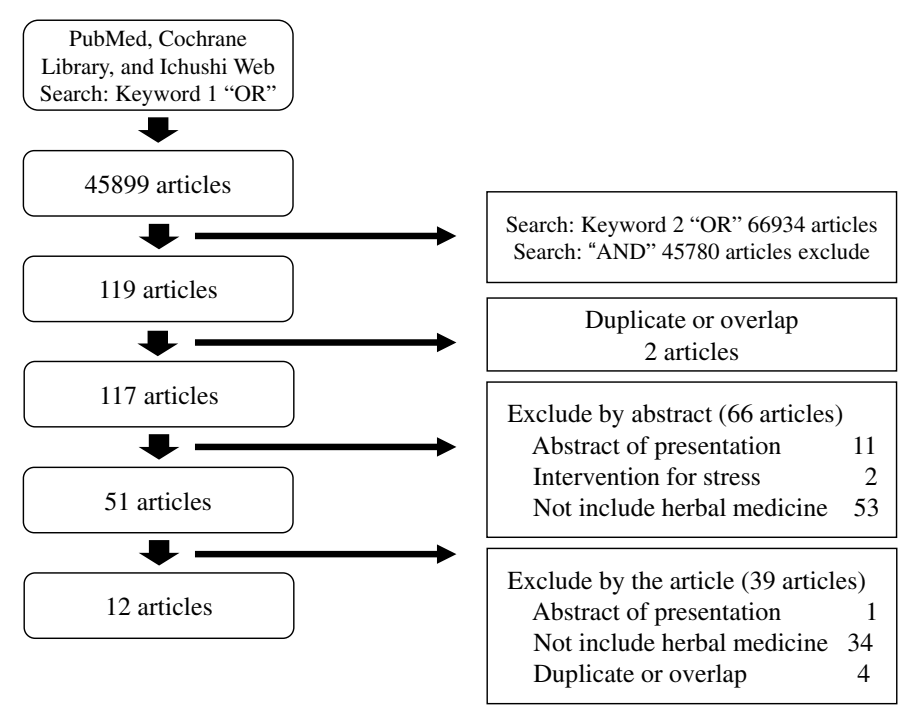

Figure 1. Review process flowchart.

(Watanabe, 2012), and common complaints (Takayama et al., 2013). Representative herbal medicines used to treat symptoms after disasters are shown in Table 2. A map of the areas affected by the large-scale earthquakes described in the articles we reviewed is shown in Fig. 2A.

\section{Herbal Medicine for PTSD}

Two articles described the effects of herbal medicine on patients with PTSD after a disaster. Meng et al. (2011) reported that the traditional Chinese medicine Xiao-Tan-Jie-Yu-Fang (XTJYF), which is related to Xiao-Yao-San (shoyosan in Japanese), was used to treat the general psychological status of survivors of the Great Sichuan earthquake with PTSD. The efficacy of this treatment was studied in a double-blind RCT involving a placebo group; the results indicated that XTJYF significantly improved the Revised Symptom Checklist-90 index, especially in cases of somatization, obsessive compulsive behavior, depression, anxiety, hostility, and sleep deprivation. Numata et al. (2014a) reported that the Kampo medicine saikokeishikankyoto (SKK) was used to treat PTSD after the Great East Japan earthquake and tsunami. The efficacy of the treatment was studied in an RCT, and results indicated that SKK significantly improved the Revised Impact of Event Scale score. A subscale analysis showed SKK significantly improved avoidance, hyperarousal, and intrusion, when compared to a control group.

\section{Herbal Medicine for Common Diseases}

Kampo medicine was used in evacuation centers after the Great East Japan earthquake and tsunami disaster. Takayama et al. (2011) reported that infectious diseases, common colds, 
HERBAL MEDICINE USES AFTER DISASTERS

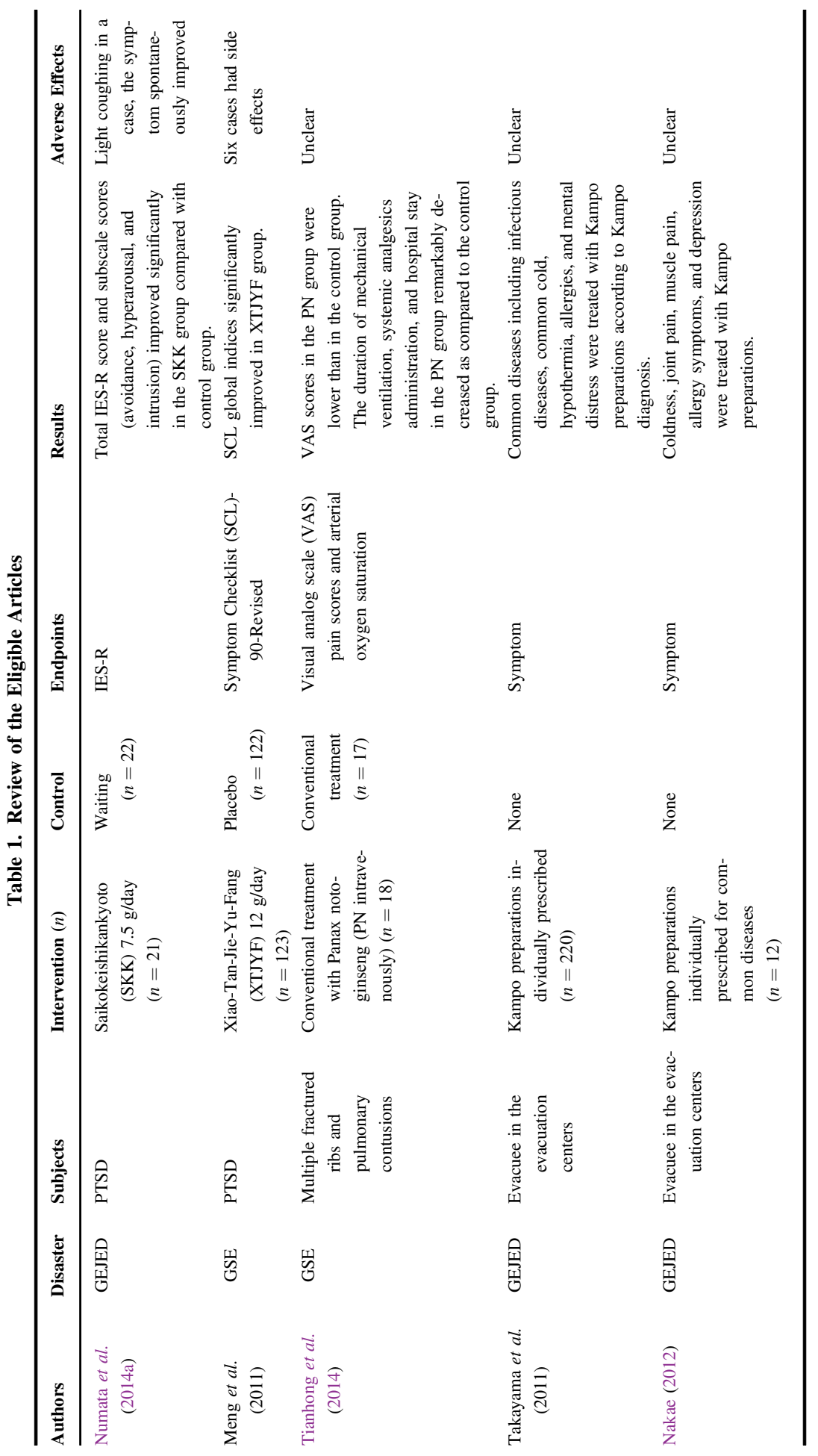




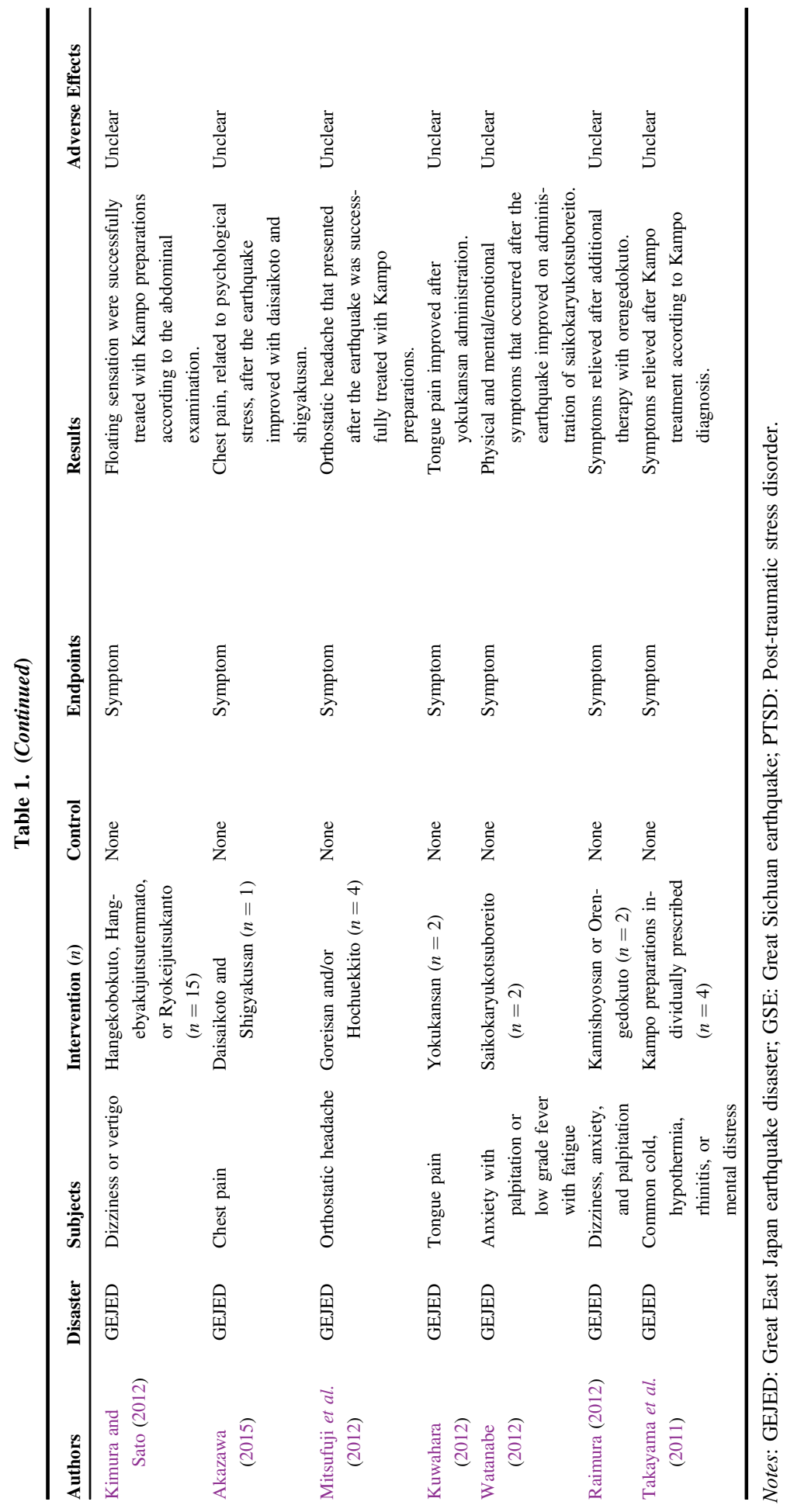


Table 2. Representative Herbal Medicines Used to Treat Various Symptoms After Disasters

\begin{tabular}{|c|c|c|c|}
\hline \multicolumn{2}{|c|}{ Diseases and Symptoms } & \multirow{2}{*}{$\begin{array}{c}\text { Herbal Medicine (in Chinese) } \\
\text { (Xiao-Tan-Jie-Yu-Fang) } \\
\text { Saikokeishikankyoto (Chai-Hu- } \\
\quad \text { Gui-Zhi-Gan-Jiang-Tang) }\end{array}$} & \multirow{2}{*}{$\begin{array}{l}\text { References } \\
\text { Meng et al. (2011) } \\
\text { Numata et al. (2014a) }\end{array}$} \\
\hline PTSD & & & \\
\hline Trauma & $\begin{array}{l}\text { Multiple fracture in } \\
\text { ribs and pulmo- } \\
\text { nary contusions }\end{array}$ & Panax notoginseng & Tianhong et al. (2014) \\
\hline \multirow[t]{15}{*}{$\begin{array}{l}\text { Common } \\
\text { diseases }\end{array}$} & Common cold & $\begin{array}{l}\text { Kakkonto (Ge-Gen-Tang) } \\
\text { Maobushisaishinto (Ma-Huang- } \\
\text { Fu-Zi-Xi-Xin-Tang) }\end{array}$ & $\begin{array}{l}\text { Takayama et al. (2011) } \\
\text { Takayama et al. (2011) }\end{array}$ \\
\hline & Tonsillitis & Kikyoto (Jie-Geng-Tang) & Takayama et al. (2011) \\
\hline & Hypothermia & $\begin{array}{l}\text { Tokishigyakukagoshuyushokyoto } \\
\text { (Dang-Qui-Si-Ni-Jia-Wu- } \\
\text { Zhu-Yu-Sheng-Jiang-Tang) }\end{array}$ & Takayama et al. (2011) \\
\hline & Enterocolitis & $\begin{array}{l}\text { Rikkunshito (Liu-Jun-Zi-Tang) } \\
\text { Goreisan (Wu-Ling-San) }\end{array}$ & $\begin{array}{l}\text { Takayama et al. (2011) } \\
\text { Miura et al. }(2011) ; \\
\text { Takayama } \text { et al. (2011) }\end{array}$ \\
\hline & Rhinitis & $\begin{array}{l}\text { Shoseiryuto (Xiao-Qing-Long- } \\
\text { Tang) }\end{array}$ & $\begin{array}{l}\text { Baba et al. (1995); Takayama } \\
\text { et al. (2011); Nakae } \\
\text { (2012) }\end{array}$ \\
\hline & Itchy eyes & $\begin{array}{l}\text { Eppikajutsuto (Yue-Bi-Jia-Zhu- } \\
\text { Tang) }\end{array}$ & Takayama et al. (2011) \\
\hline & Dry cough & $\begin{array}{l}\text { Bakumondoto (Mai-Men-Dong- } \\
\text { Tang) }\end{array}$ & $\begin{array}{l}\text { Fujimori et al. (2001); } \\
\text { Mukaida et al. (2011); } \\
\text { Takayama et al. (2011) }\end{array}$ \\
\hline & Constipation & Mashiningan (Ma-Zi-Ren-Wan) & $\begin{array}{l}\text { Cheng et al. (2011); } \\
\text { Takayama et al. (2011) }\end{array}$ \\
\hline & Insomnia & Sansoninto (Suan-Zao-Ren-Tang) & Takayama et al. (2011) \\
\hline & Irritation & Yokukansan (Yi-Gan-San) & $\begin{array}{l}\text { Iwasaki et al. (2005); } \\
\text { Matsuda et al. (2013); } \\
\text { Takayama et al. (2011); } \\
\text { Hyde et al. (2017) }\end{array}$ \\
\hline & Anxiety & $\begin{array}{l}\text { Kamikihito (Jia-Wei-Qui-Pi- } \\
\text { Tang) }\end{array}$ & Takayama et al. (2011) \\
\hline & Fatigue & $\begin{array}{l}\text { Hochuekkito (Bu-Zhong-Yi-Qi- } \\
\text { Tang) }\end{array}$ & $\begin{array}{l}\text { Tatsumi et al. (2009); } \\
\text { Takayama et al. (2011); } \\
\text { Nakae (2012) }\end{array}$ \\
\hline & Abdominal pain & $\begin{array}{l}\text { Daikenchuto (Da-Jian-Zhong- } \\
\text { Tang) }\end{array}$ & $\begin{array}{l}\text { Takayama et al. (2011); } \\
\text { Nakae (2012); Numata } \\
\text { et al. (2014a) }\end{array}$ \\
\hline & $\begin{array}{l}\text { Leg edema or numb- } \\
\text { ness of lower ex- } \\
\text { tremities }\end{array}$ & $\begin{array}{l}\text { Goshajinkigan (Niu-Che-Shen- } \\
\text { Qi-Wan) }\end{array}$ & Nakae (2012) \\
\hline & $\begin{array}{c}\text { Cramping in the } \\
\text { calves }\end{array}$ & $\begin{array}{l}\text { Shakuyakukanzoto (Shao-Yao- } \\
\text { Gan-Cao-Tang) }\end{array}$ & $\begin{array}{l}\text { Kumuta et al. (1999); Nakae } \\
\text { (2012) }\end{array}$ \\
\hline
\end{tabular}


Table 2. (Continued)

\begin{tabular}{|c|c|c|c|}
\hline \multicolumn{2}{|c|}{ Diseases and Symptoms } & \multirow{2}{*}{$\begin{array}{l}\text { Herbal Medicine (in Chinese) } \\
\text { Hangekobokuto (Ban-Xia-Hou- } \\
\text { Po-Tang) }\end{array}$} & \multirow{2}{*}{$\begin{array}{l}\text { References } \\
\text { Kimura and Sato (2012) }\end{array}$} \\
\hline \multirow{4}{*}{\multicolumn{2}{|c|}{$\begin{array}{l}\text { Dizziness or } \\
\text { vertigo }\end{array}$}} & & \\
\hline & & $\begin{array}{l}\text { Hangebyakujutsutemmato (Ban- } \\
\text { Xia-Bai-Zhu-Tian-Ma-Tang) }\end{array}$ & Kimura and Sato (2012) \\
\hline & & $\begin{array}{l}\text { Ryokeijutsukanto (Ling-Qui-Zhu- } \\
\text { Gan-Tang) }\end{array}$ & Kimura and Sato (2012) \\
\hline & & $\begin{array}{l}\text { Orengedokuto (Huang-Lian-Jie- } \\
\text { Du-Tang) }\end{array}$ & Raimura (2012) \\
\hline \multirow[t]{2}{*}{ Pain } & Chest pain & Daisaikoto (Da-Chai-Hu-Tang) & Akazawa (2015) \\
\hline & Tongue pain & Yokukansan (Yi-Gan-San) & Kuwahara (2012) \\
\hline $\begin{array}{l}\text { Psychosomatic } \\
\text { symptoms }\end{array}$ & $\begin{array}{l}\text { Anxiety, low grade } \\
\text { fever, fatigue, } \\
\text { coldness, sweat- } \\
\text { ing, dry mouth, } \\
\text { shoulder stiffness } \\
\text { and dizziness }\end{array}$ & $\begin{array}{l}\text { Saikokaryukotsuboreito (Chai- } \\
\text { Hu-Jia-Long-Gu-Mu-Li- } \\
\text { Tang) }\end{array}$ & Watanabe (2012) \\
\hline
\end{tabular}

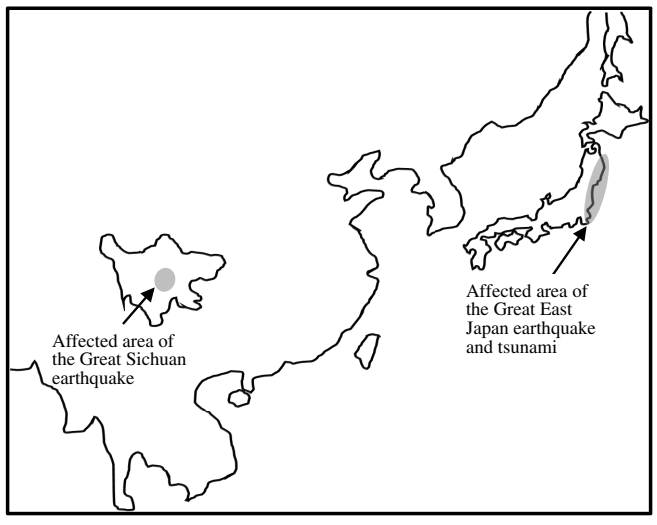

(A)

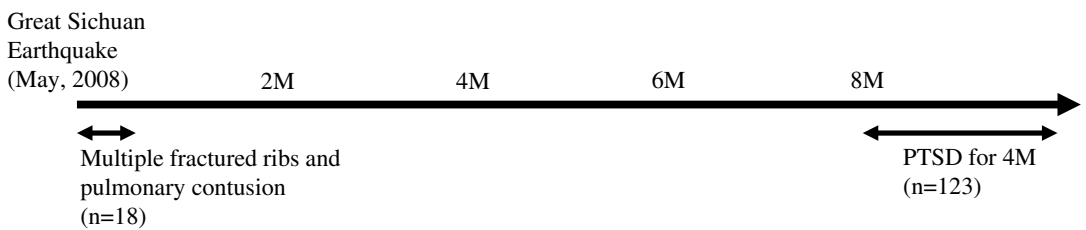

(B)

Figure 2. A map of the affected areas in the Great Sichuan earthquake and the Great East Japan earthquake and tsunami (A), intervention and investigation period of herbal medicine treatment after the Great Sichuan earthquake (B), and after the Great East Japan earthquake and tsunami (C). 


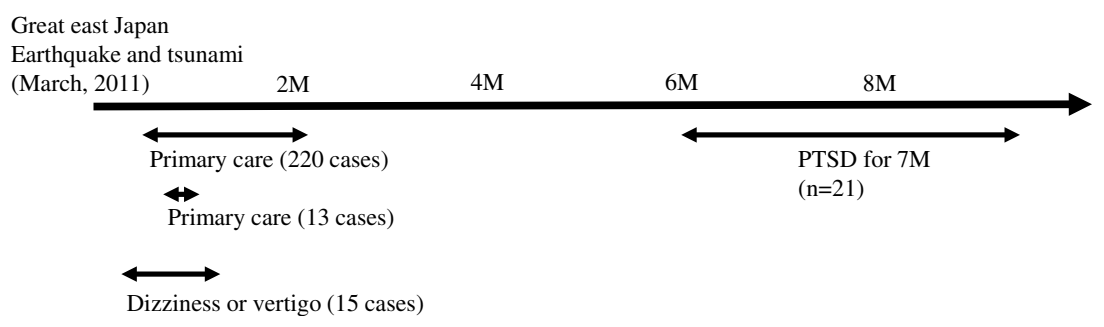

(C)

Figure 2. (Continued)

and hypothermia were frequent during the first two weeks after the disaster; allergy symptoms increased two weeks later, and mental distress was commonly observed six weeks later. A total of 220 cases were treated with Kampo medicine. The same authors reported four patients treated with Kampo medicine for the common cold, hypothermia, allergic symptoms, and psychosomatic symptoms (Takayama et al., 2013). Nakae et al. (2012) reported 13 cases treated with Kampo medicine for symptoms of coldness, joint pain, muscle pain, allergy, and depression.

Herbal Medicine for Dizziness or Vertigo

Dizziness or vertigo increased after the Great East Japan Earthquake due to multiple aftershocks. Kimura and Sato (2012) reported treating patients with dizziness or vertigo after the earthquake with hangekobokuto (12 cases), hangebyakujutsutemmato (two cases), and ryokeijutsukanto (one case).

\section{Herbal Medicine for Trauma}

Tianhong et al. (2014) reported the effect of Panax notoginseng Radix in survivors of the Great Sichuan earthquake with multiple rib fractures and pulmonary contusions. In a retrospective study, the combination of Panax notoginseng Radix and conventional treatment was compared with conventional treatment alone. Visual analogue scales of pain were lower in the combination group at one and two weeks. In the combination group, the duration of mechanical ventilation, systemic analgesia administration, and hospital stay was significantly lower than in the conventional treatment group.

\section{Herbal Medicine for Pain Management}

Seven cases of pain were treated with Kampo medicine; chest pain was treated using daisaikoto in one case (Akazawa, 2015), tongue pain using yokukansan in two cases (Kuwahara, 2012), and orthostatic headache using hochuekkito and goreisan in four cases (Mitsufuji et al., 2012). 
Table 3. Characteristics of the Great Sichuan Earthquake and the Great East Japan Earthquake and Tsunami Disasters

\begin{tabular}{lcc}
\hline & Great Sichuan Earthquake & $\begin{array}{c}\text { Great East Japan Earthquake } \\
\text { and Tsunami }\end{array}$ \\
\hline Type of earthquake & Inland crustal earthquake & Megathrust earthquake \\
Date & $5 / 12 / 2008$ & $3 / 11 / 2011$ \\
Scale & Moment magnitude 7.9 & Moment magnitude 9.0 \\
Death or missing & 87,476 & 18,455 \\
Main cause of death & Crushed to death & Drowning by tsunami \\
Collapsed or damaged houses & $4,366,000$ & 400,326 \\
Evacuees & $15,147,400$ & 470,000 \\
\hline
\end{tabular}

Herbal Medicine for Psychosomatic Symptoms

Multiple psychosomatic symptoms, including anxiety, low-grade fever, fatigue, coldness, sweating, dry mouth, shoulder stiffness, and dizziness were treated with saikokaryukotsuboreito in two cases (Watanabe, 2012).

\section{Intervention Period}

Figures $2 \mathrm{~B}$ and $2 \mathrm{C}$ show the intervention or investigation periods of herbal medicine treatment after the Great Sichuan earthquake (B) and the Great East Japan earthquakes and tsunami (C). Herbal medicine was used for the first two months to treat trauma, and for primary care in hospitals and evacuation centers. However, treatment for PTSD began 6-8 months after the disaster. The characteristics of the two major disasters are described in Table 3.

\section{Adverse Effects of Herbal Medicine}

Two RCTs reported side effects; the others were unclear in this regard. Nausea, diarrhea, and malaise were observed with the use of XTJYF, but the symptoms were not considered serious, and there were no significant differences between the XTJYF and placebo groups (Meng et al., 2011). Light coughing occurred in one case; however, this symptom spontaneously resolved after the SKK was discontinued (Numata et al., 2014a).

\section{Discussion}

\section{Interpretation of Results}

Herbal medicine has been used to treat PTSD, trauma, common complaints, dizziness and vertigo, pain, and psychosomatic symptoms. Two articles were RCTs, while the others were investigative studies. The evidence was insufficient to assess the effectiveness of herbal medicine for the treatment of various symptoms or diseases after large-scale disasters. 
Prior Studies Regarding the Evidence and Effectiveness of Herbal Medicine Post-Traumatic Stress Disorder

Two articles described the effects of herbal medicine on patients with PTSD. Meng et al. (2011) reported the efficacy of XTJYF to treat the general psychological state, and Numata et al. (2014a) described the efficacy of SKK to treat PTSD. In a rat model of chronic stress, XTJYF upregulated the expression of serotonin (5-hydroxytryptamine; 5-HT) 1A receptor in the hippocampus, potentially suppressing depression in PTSD (Xiu et al., 2007). The formula is a modification of Xiao-Yao-San (Free and Easy Wanderer) (shoyosan in Japanese), which consists of eight herbs: Bupleuri Radix, Angelicae sinensis Radix, Poria, Atractylodis macrocephalae Rhizoma, Paeonia alba Radix, Menthae Herba, Glycyrrhizae Radix Praeparata, and Zingiberis rhizoma. A modified form of Xiao-Yao-San, XTJYF is made by adding additional herbs including Ostreae Concha, Os Draconis, Rhei Radix et Rhizoma Praeparata, Acori graminei Rhizoma, Coptidis Rhizoma, Pinelliae Rhizoma Praeparata, and Citri reticulatae Pericarpium. There are more pharmacological studies on Xiao-Yao-San than on XTJYF. Xiao-Yao-San is reported to be involved in the upregulation of the expression of serotonin receptors (Bao et al., 2008) and the $\alpha$-amino-3-hydroxy-5methyl-4-isoxazole-propionate (AMPA) receptor subunit GluR2/3. The expression of the protein interacting with protein kinase $\mathrm{C}$ alpha is downregulated by Xiao-Yao-San (Yue et al., 2007). Xu et al. (2011) reported that Xiao-Yao-San maintained the stability of hippocampal neurons and inhibited the hypothalamic-pituitary-adrenocortical axis negative feedback regulation (Xu et al., 2009). Another formula made by modifying Xiao-Yao-San is called Free and Easy Wanderer Plus. Free and Easy Wanderer consisted of the eight herbs of Xiao-Yao-San, and three additional herbs, Scutellariae Radix, Moutan Cortex, and Gardeniae Fructus (Zhang et al., 2007). Free and Easy Wanderer improves PTSD-like behavior in stressed rats (Qiu et al., 2015; Wang et al., 2009) by stimulating allopregnanolone biosynthesis (Wang et al., 2009).

Pharmacological studies revealed the mechanisms of SKK. Administration of SKK for 14 days significantly increased serotonin in the hippocampus and the corpus striatum, and norepinephrine in the hippocampus (Itoh et al., 1996). SKK also regulates the levels of plasma interleukin- 6 and the concentration of soluble interleukin- 6 receptors, and improves the depressed mood of climacteric women with insomnia (Ushiroyama et al., 2005). PTSD is associated with increased levels of inflammatory markers, including interleukin-6 and tumor necrosis factor alpha (Passos et al., 2015), suggesting that PTSD may be related to chronic low-grade inflammation. SKK may decrease symptoms of PTSD by altering levels of neurotransmitters and decreasing inflammation.

\section{Trauma, Pain, and Cramping}

In Japan, jidabokuippo (Zhi-Da-Po-Yi-Fang) has been used to alleviate pain and swelling after trauma. In an RCT, Nakae et al. (2012) reported that treatment of rib fracture with jidabokuippo resulted in shorter duration of treatment and decreased healthcare expenditure, when compared to treatment with nonsteroidal anti-inflammatory drugs. 
Takeda (2010) reported that jidabokuippo was more effective for alleviating pain and swelling after injury of the lateral ankle ligaments than Loxoprofen Sodium Hydrate. Shakuyakukanzoto has been used for the treatment of cramping. In a double blind RCT, Kumada et al. (1999) reported the efficacy of shakuyakukanzoto for cramping in patients with cirrhosis. The cramping score significantly improved in the shakuyakukanzoto group, when compared to the placebo group. Two components included in shakuyakukanzoto are believed to improve muscle cramping: Glycyrrhizae Radix promotes opening of extracellular potassium channels, and Peoniae decreases inflow of intracellular calcium (Kimura, 1992).

\section{Common Cold}

Ephedrae Herba and/or Cinnamoni Cortex are used during the early phases of the common cold. In addition, Okabayashi et al. (2014) reported on the effects of kakkonto on the common cold. An RCT comparing kakkonto with multiple Western-style cold medicines demonstrated no difference in the ability to alleviate common cold symptoms, including coldness, nasal, throat, or bronchial symptoms. Furthermore, Chang et al. (2012) reported that in cell lines from human upper and lower respiratory tracts, kakkonto inhibited respiratory syncytial virus-induced plaque formation in a dose-dependent fashion. Kakkonto enhanced phagocytic activity of macrophages, an in vivo defense mechanism, suggesting that kakkonto suppresses replication of the common cold and influenza viruses. In addition, kakkonto exhibited antiviral and anti-inflammatory effects, followed by a reduction in cold symptoms, while multiple Western-style cold medicines suppressed cold symptoms. Nabeshima et al. (2012) and Kubo et al. (2007) reported that maoto (Ma-Huang-Tang), which includes the components of kakkonto, shortened the duration of fever during an influenza infection. The effect is similar to that of neuraminidase inhibitors reported in RCTs.

\section{Enterocolitis}

In an RCT, Miura et al. (2011) reported the effectiveness of goreisan to treat norovirusinduced enterocolitis. When compared to conservative care, goreisan significantly shortened the duration of vomiting, diarrhea, and abdominal pain (vomiting in the goreisan group: $79 \mathrm{~min}$, conservative group: $1702 \mathrm{~min}$; diarrhea: $110 \mathrm{~min}$ vs. $1728 \mathrm{~min}$; abdominal pain: $122 \mathrm{~min}$ vs. $1813 \mathrm{~min}$ ).

\section{Rhinitis}

A double-blind trial using shoseiryuto and placebo for treatment of perennial allergic rhinitis included 220 patients. Administration of shoseiryuto for two weeks alleviated symptoms including spasmodic sneezing, mucus production, and rhinostenosis ( $p<0.001$ ) (Baba et al., 1995). Shoseiryuto decreased the number of T-helper 2 (Th2) cells and the level of interleukin-4. Th1 cells were not altered (Ko et al., 2004). 
Antihistamines are recommended as a standard therapy for allergic rhinitis (Bousquet et al., 2012). Although side effects, such as sleepiness, have decreased with the development of newer drugs, side effects still exist. Since shoseiryuto does not affect histamine H1 receptors, there are fewer effects such as sedation and drowsiness (Sakaguchi et al., 1996).

\section{Cough}

Bakumondoto is a traditional herbal medicine used for the treatment of bronchitis, bronchial asthma, and cough. In an RCT, Fujimori et al. (2001) reported that compared to dextromethorphan hydrobromide, bakumondoto was more effective in treating post-infectious cough. Mukaida et al. (2011) showed that bakumondoto was effective in suppressing cough in elderly patients diagnosed with chronic obstructive pulmonary disease. Glycyrrhizae Radix, one of herbs contained in bakumondoto, may have a persistent antitussive effect, and the metabolites liquiritin apioside and liquiritigenin, may be involved in these effects. Ophiopogonis Radix, another herb in bakumondoto, has anti-inflammatory activity, and ruscogenin and ophiopogonin D are two of its active components.

\section{Irritation}

Iwasaki et al. (2005) reported that yokukansan improved the behavioral and psychological symptoms of dementia, such as hallucinations, delusions, agitation, and aggression. Two meta-analyses examined the effect of yokukansan on behavioral and psychological symptoms of dementia (Matsuda et al., 2013; Hyde et al., 2017). Yokukansan did not increase extrapyramidal symptoms. Yokukansan controls the concentration of serotonin in the synaptic cleft via partial agonist of 5-HT1A receptors (Terawaki et al., 2016), and 5-HT2A receptor expressions are downregulated by yokukansan (Egashira et al., 2008). Yokukansan inhibits the release of glutamate resulting in a decreased concentration of glutamate at synaptic clefts in the brain, and promotes glutamate uptake by astrocytes (Takeda et al., 2008a, 2008b; Kawakami et al., 2010).

\section{Fatigue}

Tatsumi et al. (2009) reported in elderly patients with chronic obstructive pulmonary disease, that hochuekkito may be superior to conventional therapy in improving fatigue and malaise, and the objective indexes of systemic inflammation and nutritional status. Hochuekkito increases titers of influenza virus-specific IgA antibody and total IgA antibody in the nasal cavity (Kiyohara et al., 2006). Furthermore, hochuekkito inhibits rhinovirus infection in human tracheal epithelial cells, by decreasing intercellular adhesion molecule-1 levels, and blocks viral RNA from entering the cytoplasm via the airway epithelial cell endosomes (Yamaya et al., 2007). Glycyrrhizin may be partly responsible for the inhibition of rhinovirus infection by hochuekkito, since it stimulates the upper respiratory tract mucosal immune system, and modulates airway inflammation by reducing cytokine production. Hochuekkito, since it stimulates the immune system, is considered a tonifying drug. 
Panax ginseng Radix and Astragali Radix, ingredients of hochuekkito, are believed to confer these effects, which correspond to "vital energy" or "signaling" in Western medicine. Tonifying drugs enhance energy uptake through digestion and absorption (in the case of Panax ginseng Radix) or through respiration (in the case of Astragali Radix). Similarly, Angelicae Radix, Paeoniae Radix, and other herbs are thought to support blood production, while Rehmanniae Radix, Ophiopogonis Radix, and others reinforce liquid formation.

\section{Functional Abdominal Pain or Constipation}

In Japan, daikenchuto is widely used to prevent ileus after abdominal surgery. Daikenchuto can be used to treat patients with pain or cold sensations in the abdomen, and those who cannot eat due to nausea. Numata et al. (2014b) reported that daikenchuto alleviated functional constipation in post-stroke patients. A subscale analysis showed that daikenchuto significantly improved constipation scores. After therapy with daikenchuto, abdominal gas volume assessed by radiographic examination was significantly reduced. Daikenchuto treats abdominal symptoms by enhancing the secretions of motilin (Nagano et al., 1999), substance P (Kono et al., 2008), calcitonin gene-related peptide, and adrenomedullin (Kono et al., 2010, 2011), and activating the transient receptor potential vanilloid (Kikuchi et al., 2013). Keishikashakuyakuto is also used to treat functional abdominal pain, and the effects on irritable bowel syndrome have been investigated in a double blind RCT (Sasaki et al., 1998). Abdominal pain in irritable bowel syndrome with diarrhea significantly decreased after keishikashakuyakuto (Gui-Zhi-Jia-Shao-YaoTang) administration, and the effect was superior to that of a placebo. Adverse effects of keishikashakuyakuto were not significantly different from placebo, suggesting that keishikashakuyakuto is safe. Effects of mashiningan have also been evaluated in a double blind RCT (Cheng et al., 2011). Increased complete spontaneous bowel movements, relief of constipation and straining, and reduction in the use of rescue therapy was noted in individuals in the mashiningan group. The results were superior to those of a placebo group, and no serious adverse effects were reported. Aurantii Fructus Immaturus, which is an ingredient of mashiningan, increases digestion and regulates bowel function, and hemp seed oil acts as a stool softener.

\section{Dizziness or Vertigo}

Nakamura et al. (2000) conducted an RCT study of goreisan for orthostatic hypotension in patients with diabetes mellitus. They reported that goreisan significantly diminished the drop in blood pressure after standing. Goreisan also improved subjective symptom of orthostatic dizziness. There are so many case reports and small size studies regarding Kampo treatments for dizziness or vertigo, since treatments for them differ depending on its causes and accompanying symptoms. Formulae for orthostatic dizziness are ryokeijutsukanto or hochuekkito. Hangebyakujutsutemmato and takushato (Ze-Xie-Tang) have been used for treating paroxysmal vertigo. If patients have dizziness with cold feelings and fluid 
retention, shinbuto (Zhen-Wu-Tang) may be used. In case of dizziness caused by mental stress, hangekobokuto and saikokaryukotsuboreito can be administered.

\section{Duration of Treatment}

Immediately after a large-scale disaster, the disaster medical assistance teams provide emergency care. These teams primarily treat trauma and crush injuries. During this period, emergency care should be a priority. Survivors are later evacuated to shelters or evacuation centers. Evacuees may experience health problems and medical support activities, including hygiene maintenance, primary care, and psychological support. Figures $2 \mathrm{~B}$ and $2 \mathrm{C}$ show that herbal medicine treatment after a disaster tends to occur in two periods. Herbal medicine was used in the evacuation center early after the disaster, and for as long as six months after the disaster for treatment for PTSD. There may have been more medical support involving herbal treatments during other treatment periods. However, they did not fall within the scope of this review.

\section{Points to Remember}

Few articles mentioned adverse effects. SKK was associated with the onset of cough in one of 27 patients; however, coughing spontaneously resolved after the treatment was discontinued (Numata et al., 2014a). SKK contains Scutellariae Radix, which has been reported to cause interstitial pneumonia in rare cases. In general, adverse effects associated with the herbal medicines are well tolerated. The Japan Geriatrics Society guidelines describe five herbs with known adverse effects: Processi Aconiti Radix, Glycyrrhizae Radix, Ephedrae Herba, Scutellariae Radix, and Gardeniae Fructus. These herbs are listed in the pharmacopeia, and adverse reactions have been reported and published by the Pharmaceutical and Medical Devices Agency. Glycyrrhizae Radix, which can cause hypokalemia, is a component of approximately $70 \%$ of herbal preparations in Japan. Prolonged and heavy use of Glycyrrhizae Radix should be avoided. If adverse effects are thought to be associated with herbal medicines, treatment should be stopped, and a proper examination should be performed.

\section{Limitations}

It is difficult to confirm the effectiveness of herbal treatments in disasters. Immediately after the disaster, rescue and relief operations are the top priority and for this reason, few studies have been carried out during this period. The studies carried out immediately after a disaster had biases in their design. Therefore, evidence for the effectiveness of herbal treatments in disaster situations is insufficient. Investigations on the effectiveness of herbal treatments should performed in less extreme situations. One common problem for both Western and traditional medicine is the insufficient transport of medicines. Furthermore, in disaster situations, clean drinking water, which is required to take some medicines, is often scarce. 


\section{Future Perspectives}

Herbal medicine may be useful to treat various symptoms and diseases after large-scale disasters. However, there have been few reports, and further studies will be needed to confirm the effectiveness of herbal treatment these situations. Nonetheless, future studies will be performed considering the feelings of the disaster victims.

In conclusion, herbal medicine has been used to treat trauma, PTSD, and other symptoms in primary care. Two of the articles reviewed were RCTs and the others were investigative studies. In disaster situations, it is difficult to design high quality studies to confirm the effectiveness of herbal medicine. Further studies will clarify the usefulness of herbal medicine in treating patients after large-scale disasters.

\section{Acknowledgments}

We would like to extend our sincere sympathies to those who have been injured by disasters throughout the world. We also express our deepest appreciation and gratitude to the people throughout the world who have offered their generous support and help after the earthquake and tsunami that affected the east coast of Japan.

This study was funded by the Tohoku University Hospital administration fund. Takehiro Numata, Akiko Kikuchi, Minoru Ohsawa, Shin Takayama, and Tadashi Ishii belong the Department of Kampo and Integrative Medicine, Tohoku University School of Medicine. The department received a grant from Tsumura, a Japanese manufacturer of Kampo medicine; however, the grant was used as per Tohoku University rules.

\section{References}

Akazawa, S. A case of chest pain related with the post-traumatic stress of large-scale earthquake successfully treated with daisaikoto and shigyakusan. Kampo-no-rinsyo 62: 1685-1690, 2015.

Baba, S., T. Takasaka, N. Inamura, M. Sato, S. Suzuki, S. Endo et al., Double-blind clinical trial of Sho-seiryu-to (TJ-19) for perennial nasal allergy. Practica oto-rhino-laryngologica 88: 389-405, 1995.

Bao, L., J. Chen, L. Huang, W. Chen, Q. Lin, X.S. Yao and K. Hiroshi. Effects of Xiaoyao Wan on the behavioral despair and stress depression mice. Zhong Yao Cai 31: 1360-1364, 2008.

Bousquet, J., H.J. Schünemann, B. Samolinski, P. Demoly, C.E. Baena-Cagnani, C. Bachert et al., World Health Organization Collaborating Center for Asthma and Rhinitis. Allergic rhinitis and its impact on asthma (ARIA): Achievements in 10 years and future needs. J. Allergy Clin. Immunol. 130: 1049-1062, 2012.

Chang, J.S., K.C. Wang, D.E. Shieh, F.F. Hsu and L.C. Chiang. Ge-Gen-Tang has anti-viral activity against human respiratory syncytial virus in human respiratory tract cell lines. J. Ethnopharmacol. 139: 305-310, 2012.

Cheng, C.W., Z.X. Bian, L.X. Zhu, J.C. Wu and J.J. Sung. Efficacy of a Chinese herbal proprietary medicine (Hemp Seed Pill) for functional constipation. Am. J. Gastroenterol. 106: 120-129, 2011.

Egashira, N., K. Iwasaki, A. Ishibashi, K. Hayakawa, R. Okuno, M. Abe, N. Uchida, K. Mishima, K. Takasaki, R. Nishimura, R. Oishi and M. Fujiwara. Repeated administration of Yokukansan 
inhibits DOI-induced head-twitch response and decreases expression of 5-hydroxytryptamine (5-HT) 2A receptors in the prefrontal cortex. Prog. Neuropsychopharmacol. Biol. Psychiatry 32: 1516-1520, 2008.

Fujimori, K., E. Uzuki and G. Fumitake. Comparison between Bakumondoto (Mai men dong tang) and dextromethorphan hydrobromide in terms of effect on post-infectious cough: A pilot study. Kampo Med. 51: 725-732, 2001.

Hyde, A.J., B.H. May, L. Dong, M. Feng, S. Liu, X. Guo, A.L. Zhang, C. Lu and C.C. Xue. Herbal medicine for management of the behavioural and psychological symptoms of dementia (BPSD): A systematic review and meta-analysis. J. Psychopharmacol. 31: 169-183, 2017.

Inoue, T., A. Nakao, K. Kuboyama, A. Hashimoto, M. Masutani, T. Ueda and J. Kotani. Gastrointestinal symptoms and food/nutrition concerns after the Great East Japan earthquake in March 2011: Survey of evacuees in a temporary shelter. Prehosp. Disaster Med. 29: 303-306, 2014.

Ishii, T. Medical response to the Great East Japan Earthquake in Ishinomaki City. Western Pac. Surveill. Response J. 2: 10-16, 2011.

Itoh, T., S. Michijiri, S. Murai, H. Saito, H. Saito, O. Itsukaichi and H. Fujiwara. Effects of chaihuguizhi-ganjiang-tang on the levels of monoamines and their related substances, and acetylcholine in discrete brain regions of mice. Am. J. Chin. Med. 24: 53-64, 1996.

Iwasaki, K., T. Satoh-Nakagawa, M. Maruyama, Y. Monma, M. Nemoto, N. Tomita, H. Tanji, H. Fujiwara, T. Seki, M. Fujii, H. Arai and H. Sasaki. A randomized, observer-blind, controlled trial of the traditional Chinese medicine Yi-Gan San for improvement of behavioral and psychological symptoms and activities of daily living in dementia patients. J. Clin. Psychiatry. 66: 248-252, 2005.

Kawakami, Z., Y. Ikarashi and Y. Kase. Glycyrrhizin and its metabolite 18 beta-glycyrrhetinic acid in glycyrrhiza, a constituent herb of yokukansan, ameliorate thiamine deficiency-induced dysfunction of glutamate transport in cultured rat cortical astrocytes. Eur. J. Pharmacol. 626: 154-158, 2010.

Kikuchi, D., C. Shibata, H. Imoto, T. Naitoh, K. Miura and M. Unno. Intragastric Dai-Kenchu-To, a Japanese herbal medicine, stimulates colonic motility via transient receptor potential cation channel subfamily V member 1 in dogs. Tohoku J. Exp. Med. 230: 197-204, 2013.

Kimura, M., The selective mechanism of pathophysiological action of Kampo formulae. Taisha 29: 9-35, 1992.

Kimura, Y. and H. Sato. Treatment of patients with floating sensation after the Great East Japan earthquake: Focusing on the efficacy of hangekobokuto. Kampo Med. 63: 37-40, 2012.

Kiyohara, H., T. Nagai, K. Munakata, K. Nonaka, T. Hanawa, S.J. Kim and H. Yamada. Stimulating effect of Japanese herbal (kampo) medicine, hochuekkito on upper respiratory mucosal immune system. Evid. Based Complement. Alternat. Med. 3: 459-467, 2006.

Ko, E., S. Rho, C. Cho, H. Choi, S. Ko, Y. Lee, M.C. Hong, M.K. Shin, S.G. Jung and H. Bae. So-Cheong-Ryong-Tang, tradititional Korean medicine, suppresses Th2 lineage development. Biol. Pharm. Bull. 27: 739-743, 2004.

Kono, T., A. Kaneko, Y. Hira, T. Suzuki, N. Chisato, N. Ohtake, N. Miura and T. Watanabe. Anticolitis and -adhesion effects of Daikenchuto via endogenous adrenomedullin enhancement in Crohn's disease mouse model. J. Crohns Colitis. 4: 161-170, 2010.

Kono, T., T. Koseki, S. Chiba, Y. Ebisawa, N. Chisato, J. Iwamoto and S. Kasai. Colonic vascular conductance increased by Daikenchuto via calcitonin gene-related peptide and receptoractivity modifying protein 1. J. Surg. Res. 150: 78-84, 2008.

Kono, T., Y. Omiya, Y. Hira, A. Kaneko, S. Chiba, T. Suzuki, M. Noguchi and T. Watanabe. Daikenchuto (TU-100) ameliorates colon microvascular dysfunction via endogenous adrenomedullin in Crohn's disease rat model. J. Gastroenterol. 46: 1187-1196, 2011. 
Kubo, T. and H. Nishimura. Antipyretic effect of Mao-to, a Japanese herbal medicine, for treatment of type A influenza infection in children. Phytomedicine 14: 96-101, 2007.

Kumada, T., H. Kumada, M. Yoshiba, S. Nakano, H. Suzuki, T. Tango, T. Kumuda and M. Yoshida. Effects of Shakuyaku-kanzo-to (Tsumura TJ-68) on muscle cramps accompanying cirrhosis in a placebo-controlled double-blind parallel study. Rinsho Iyaku 15: 499-523, 1999.

Kuwahara, T. Two cases in which Yokukansan was effective for treating unidentified oral complaints related to the Great East Japan earthquake. J. Jpn. Assn. Oriental Psychosom. Med. 27: 61-63, 2012.

Liu, M., M. Kohzuki, A. Hamamura, M. Ishikawa, M. Saitoh, M. Kurihara, K. Handa, H. Nakamura, J. Fukaura, R. Kimura, T. Ito and N. Matsuzaka. How did rehabilitation professionals act when faced with the Great East Japan earthquake and disaster? Descriptive epidemiology of disability and an interim report of the relief activities of the ten rehabilitation-related organizations. J. Rehabil. Med. 44: 421-428, 2012.

Matsuda, Y., T. Kishi, H. Shibayama and N. Iwata. Yokukansan in the treatment of behavioral and psychological symptoms of dementia: A systematic review and meta-analysis of randomized controlled trials. Hum. Psychopharmacol. 28: 80-86, 2013.

Meng, X.Z., F. Wu, P.K. Wei, L.J. Xiu, J. Shi, B. Pang, S.D. Sun, Z.F. Qin, Y. Huang and L. Lao. A Chinese herbal formula to improve general psychological status in posttraumatic stress disorder: A randomized placebo-controlled trial on Sichuan earthquake survivors. Evid. Based Complement. Alternat. Med. 2011: 691258, 2011.

Mitsufuji, T., T. Yamamoto, Y. Mizoi, N. Tamura and N. Araki. Kampo medicine is effective to four cases of migraine complicated with orthostatic dysregulation after Great East Japan earthquake. Jpn. J. Psychosom. Med. 27: 38-40, 2012.

Miura, Y., Y. Yamagishi, H. Mikamo and K. Izumi. Investigation of the effects of Kampo medicine for infectious diarrhea. Sanhujinka-kanponoayumi 28: 102-104, 2011.

Mukaida, K., N. Hattori, K. Kondo, N. Morita, I. Murakami, Y. Haruta, A. Yokoyama and N. Kohno. A pilot study of the multiherb Kampo medicine bakumondoto for cough in patients with chronic obstructive pulmonary disease. Phytomedicine 18: 625-629, 2011.

Nabeshima, S., K. Kashiwagi, K. Ajisaka, S. Masui, H. Takeoka, H. Ikematsu and S. Kashiwagi. A randomized, controlled trial comparing traditional herbal medicine and neuraminidase inhibitors in the treatment of seasonal influenza. J. Infect. Chemother. 18: 534-543, 2012.

Nagano, T., H. Itoh and M. Takeyama. Effect of Dai-kenchu-to on levels of 3 brain-gut peptides (motilin, gastrin and somatostatin) in human plasma. Biol. Pharm. Bull. 22: 1131-1133, 1999.

Nakae, H. Role of traditional Japanese medicines in the relief effort in areas affected by the Great East Japan earthquake. Personalized Med. Universe. 1: 45-48, 2012.

Nakae, H., A. Yokoi, H. Kodama and A. Horikawa. Comparison of the effects on rib fracture between the traditional Japanese medicine Jidabokuippo and nonsteroidal anti-inflammatory drugs: A randomized controlled trial. Evid. Based Complement. Alternat. Med. 2012: 837958, 2012.

Nakamura, H., T. Nakamura, S. Nakagawa and Y. Aizawa. The effect of goreisan for orthostatic hypotension in the patients of diabetes mellitus. Diabetes Frontier 11: 561-563, 2000.

Numata, T., S. Gunfan, S. Takayama, S. Takahashi, Y. Monma, S. Kaneko, H. Kuroda, J. Tanaka, S. Kanemura, M. Nara, Y. Kagaya, T. Ishii, N. Yaegashi, M. Kohzuki and K. Iwasaki. Treatment of posttraumatic stress disorder using the traditional Japanese herbal medicine saikokeishikankyoto: A randomized, observer-blinded, controlled trial in survivors of the Great East Japan earthquake and tsunami. Evid. Based Complement. Alternat. Med. 2014: 683293, 2014a.

Numata, T., S. Takayama, M. Tobita, S. Ishida, D. Katayose, M. Shinkawa, T. Oikawa, T. Aonuma, S. Kaneko, J. Tanaka, S. Kanemura, K. Iwasaki, T. Ishii and N. Yaegashi. Traditional Japanese medicine daikenchuto improves functional constipation in post-stroke patients. Evid. Based Complem. Alternat. Med. 2014: 231258, 2014b. 
Okabayashi, S., M. Goto, T. Kawamura, H. Watanabe, A. Kimura, R. Uruma, Y. Takahashi, S. Taneichi, M. Musashi and K. Miyaki. Non-superiority of Kakkonto, a Japanese herbal medicine, to a representative multiple cold medicine with respect to anti-aggravation effects on the common cold: A randomized controlled trial. Intern. Med. 53: 949-956, 2014.

Passos, I.C., M.P. Vasconcelos-Moreno, L.G. Costa, M. Kunz, E. Brietzke, J. Quevedo, G. Salum, P.V. Magalhães, F. Kapczinski and M. Kauer-Sant'Anna. Inflammatory markers in posttraumatic stress disorder: A systematic review, meta-analysis, and meta-regression. Lancet Psychiatry 2: 1002-1012, 2015.

Qiu, Z.K., G.H. Zhang, J.L. He, J.C. Ma, J. Zeng, D. Shen, Y.G. Shen, J.S. Chen and C.Y. Liu. Free and Easy Wanderer Plus (FEWP) improves behavioral deficits in an animal model of posttraumatic stress disorder by stimulating allopregnanolone biosynthesis. Neurosci. Lett. 602: 162-166, 2015.

Raimura, M. Efficacy of capsule of orengedokuto in the Great East Japan earthquake. Kampokenkyu 483: 10-1, 2012.

Sakaguchi, M., A. Iizuka, M. Yuzurihara, A. Ishige, Y. Komatsu, T. Matsumiya and H. Takeda. Pharmacological characteristics of Sho-seiryu-to, an antiallergic Kampo medicine without effects on histamine H1 receptors and muscarinic cholinergic system in the brain. Methods Find. Exp. Clin. Pharmacol. 18: 41-47, 1996.

Sasaki, D., S. Uehara, N. Hiwatashi, T. Sekiguchi, A. Nakahara, Y. Nakai, M. Mizuno, N. Morita, M. Namiki and S. Nakano. Clinical effect of keishikasyakuyakuto for irritable bowel syndrome. A multicenter randomized controlled trial. Rinsyo-to-kenkyu 75: 1136-1152, 1998.

Takayama, S., K. Watanabe, K. Iwasaki, T. Numata and N. Yaegashi. Japanese Kampo medicine after the Great East Japan earthquake in Miyagi and Fukushima prefectures. $T$ J Kampo Acupuncture Integrative Med. 6: 1-8, 2013.

Takayama, S., R. Okitsu, K. Iwasaki, M. Watanabe, T. Kamiya, A. Hirano, A. Matsuda, Y. Monma, T. Numata, H. Kusuyama, S. Hirata, A. Kikuchi, T. Seki, T. Takeda and N. Yaegashi. The role of oriental medicine in the Great East Japan earthquake disaster. Kampo Med. 62: 621-626, 2011.

Takeda, A., H. Itoh, H. Tamano, M. Yuzurihara and N. Oku. Suppressive effect of Yokukansan on excessive release of glutamate and aspartate in the hippocampus of zinc-deficient rats. Nutr. Neurosci. 11: 41-46, 2008a.

Takeda, A., H. Tamano, H. Itoh and N. Oku. Attenuation of abnormal glutamate release in zinc deficiency by zinc and Yokukansan. Neurochem. Int. 53: 230-235, 2008b.

Takeda, N., Conservative therapy for injury of the lateral ankle ligaments - Comparison of Western medicine with Kampo medicine for alleviating pain and swelling. Kampo-to-Shinryo 1: 128$132,2010$.

Tatsumi, K., N. Shinozuka, K. Nakayama, N. Sekiya, T. Kuriyama and Y. Fukuchi. Hochuekkito improves systemic inflammation and nutritional status in elderly patients with chronic obstructive pulmonary disease. J. Am. Geriatr. Soc. 57: 169-170, 2009.

Terawaki, K., Y. Ikarashi, K. Sekiguchi, Y. Nakai and Y. Kase. Partial agonistic effect of yokukansan on human recombinant serotonin 1A receptors expressed in the membranes of Chinese hamster ovary cells. J. Ethnopharmacol. 127: 306-312, 2010.

Tianhong, M., Q. Yuxi, W. Zhimin and Y. Baili. Effect of Panax notoginseng in patients with multiple fractured ribs and pulmonary contusions caused by the 2008 Wenchuan earthquake. Forsch. Komplementmed. 21: 360-364, 2014.

Tokuda, K., H. Kunishima, Y. Gu, S. Endo, M. Hatta, H. Kanamori, T. Aoyagi, N. Ishibashi, S. Inomata, H. Yano, M. Kitagawa and M. Kaku. A survey conducted immediately after the 2011 Great East Japan earthquake: Evaluation of infectious risks associated with sanitary conditions in evacuation centers. J. Infect. Chemother. 20: 498-501, 2014. 
Ushiroyama, T., A. Ikeda, K. Sakuma and M. Ueki. Chai-hu-gui-zhi-gan-jiang-tang regulates plasma interleukin-6 and soluble interleukin-6 receptor concentrations and improves depressed mood in climacteric women with insomnia. Am. J. Chin. Med. 33: 703-711, 2005.

Wang, H.N., Y. Peng, Q.R. Tan, H.H. Wang, Y.C. Chen, R.G. Zhang, Z.Z. Wang, L. Guo, Y. Liu and Z.J. Zhang. Free and Easy Wanderer Plus (FEWP), a polyherbal preparation, ameliorates PTSD-like behavior and cognitive impairments in stressed rats. Prog. Neuropsychopharmacol. Biol. Psychiatry 33: 1458-1463, 2009.

Watanabe, K., Two cases of mental anxiety related with the Great East Japan earthquake successfully treated with saikokaryukotsuboreito. Sanfujinnka-kampo-kenkyu-no-ayumi 29: 48-49, 2012.

Xiu, L.J., P.K. Wei and L. Liu. Influence of traditional Chinese recipe Xiaotanjieyu decoction on behavior of mice after chronic swimming stress and on expression of 5-HT1A receptor mRNA in their hippocampus. Acad. J. Second Mil. Med. Univ. 28: 1126-1128, 2007.

Xu, Z.W., Q. Sun, H.Q. Ao, W.Z. Wang and W.J. Fu. Effects of Xiaoyao powder on NR1, NR2A and NR2B mRNA expression in cultured hippocampal neurons of rats under chronic stress. J. Guangzhou Univ. Tradit. Chin. Med. 28: 36-42, 2011.

Xu, Z.W., W.J. Fu and H.Q. Ao. Effect of Xiaoyaosan on HPA axis negative feedback regulation function of rats with chronic stress. J. Shanxi Coll. Tradit. Chin. Med. 10: 15-17, 2009.

Yamaya, M., T. Sasaki, H. Yasuda, D. Inoue, T. Suzuki, M. Asada, M. Yoshida, T. Seki, K. Iwasaki, H. Nishimura and K. Nakayama. Hochu-ekki-to inhibits rhinovirus infection in human tracheal epithelial cells. Br. J. Pharmacol. 150: 702-710, 2007.

Yue, G.X., Z.F. Wang, Q.L. Zhang, X. Zhao, L.F. Yue and J. Ding. Changes of AMPA receptors and related protein in immobilization stress rats and effect of Xiaoyao powder. J. Beijing Univ. Tradit. Chin. Med. 30: 603-607, 2007.

Zhang, Z.J., W.H. Kang, Q. Li and Q.R. Tan. The beneficial effects of the herbal medicine Free and Easy Wanderer Plus (FEWP) for mood disorders: Double-blind, placebo-controlled studies. J. Psychiatr. Res. 41: 828-836, 2007. 